\title{
Assessing lead exposure sources at the property scale in Indianapolis
}

\author{
Emily Hentz ${ }^{1}$, BS; Gabriel Filippelli², PhD; Noah Springer ${ }^{3}$, Emily Hopkins ${ }^{4}$, MA, \\ BS, BA; Isheka Orr ${ }^{5}$, Rachel Smith ${ }^{6}$, BA \\ ${ }^{1}$ Indiana University School of Medicine, ${ }^{2}$ Indiana University-Purdue University, \\ Department of Earth Sciences and Center for Urban Health, ${ }^{3}$ University of Notre \\ Dame, ${ }^{4}$ Indy Star, ${ }^{5}$ Claflin University, ${ }^{6}$ University of Georgia, Odum School of \\ Ecology
}

\section{Background and Hypothesis:}

Lead $(\mathrm{Pb})$ was phased out of paint and gasoline over 40 years ago due to neurotoxicity in humans, but has persisted in soils and poses a legacy threat to many. The Indianapolis 46218 zip code has had $>10 \%$ children exhibiting $\mathrm{Pb}$ poisoning. This zip code has had historically high soil $\mathrm{Pb}$ levels, and is undergoing redevelopment. We hypothesize that redevelopment will act to reexpose new populations of people to the legacy $\mathrm{Pb}$ present in the area.

\section{Experimental Design or Project Methods:}

We sampled 5 parks and 7 playgrounds. Stratified random sampling based on permit type was used to select properties from 25 issued and 25 closed permits from 527 identified demolition permits. Nearby residential properties were selected, with permission of residents. Samples were taken near the dripline of the house, front yard, and street, or from each quadrant at sites without houses. Samples were dried, crushed, sieved to 150 microns, and assessed using X-Ray Fluorescence.

\section{Results:}

Mean $\mathrm{Pb}$ levels from driplines (1026 ppm) were significantly higher than streets $(p=0.001)$, parks $(p=0.002)$, yards $(p=0.001)$, and demolition sites $(p=0.000) . P b$ concentrations for playgrounds had the lowest median lead levels (42 ppm), while dripline samples had the highest (289 ppm). The EPA standard for children's play areas is 400 ppm.

\section{Conclusion and Potential Impact:}

While all samples from playgrounds were below 400 ppm, children are also likely playing at their homes, where no legislation effectively protects them from potential $\mathrm{Pb}$ poisoning and values were found above $400 \mathrm{ppm}$. An immediate outcome from this project is the education. Residents who agreed to testing $(\mathrm{n}=42)$ received results of the test and guidelines to prevent $\mathrm{Pb}$ poisoning. More work remains to ensure preventive rather than reactive strategies are employed to protect children's health. 